\title{
Weldability of Ti and Al Dissimilar Metals Using Single-Mode Fiber Laser
}

\author{
Su-Jin Lee ${ }^{* 1}$, Hiroshi Nakamura ${ }^{* 1}$, Yousuke Kawahito ${ }^{* 1}$ and Seiji Katayama ${ }^{* 1}$ \\ ${ }^{* 1}$ Joining and Welding Research Institute (JWRI), Osaka University, \\ 11-1 Mihogaoka, Ibaraki, Osaka 567-0047, JAPAN
}

\begin{abstract}
$\mathrm{Ti}$ and $\mathrm{Al}$ have great differences in lattice structure, melting point, heat conductivity, coefficient of linear expansion, etc., and $\mathrm{Ti}$ and $\mathrm{Al}$ intermetallic compounds such as $\mathrm{Ti}_{3} \mathrm{Al}, \mathrm{TiAl}, \mathrm{TiAl}_{3}$ are easily formed at the contacting surface between $\mathrm{Ti}$ and $\mathrm{Al}$. Thus, welding or joining of $\mathrm{Ti}$ and $\mathrm{Al}$ is considered to be extremely difficult. Nevertheless, in this study, dissimilar welding of Ti and Al using single-mode fiber laser with extremely high welding speed was tried, and the microstructural characteristics of the interface zone in $\mathrm{Ti}$ and $\mathrm{Al}$ weld were investigated. Especially, full penetration lap welding of $\mathrm{Ti}$ and $\mathrm{Al}$ was tried with single-mode fiber laser. The strengths of the dissimilar weld were evaluated by the tensile shear test. To recognize the formation of intermetallic phases in the weld fusion zone and the relationship between intermetallic phases and the tensile strength, the lapwelded areas of Ti and $\mathrm{Al}$ sheets were observed by scanning electron microscope (SEM) and analyzed by using X-ray diffractometer (XRD). The research results suggest a great formation possibility of a strong Ti/Al dissimilar weld with intermetallic compounds reduced by using a single-mode fiber laser under the condition of an extremely high welding speed.

DOI:10.2961/jlmn.2013.02.0006
\end{abstract}

Keywords: Ti, Al, Dissimilar welding, Single-mode fiber laser, Intermetallic compound, Weldability

\section{Introduction}

The weight reduction is strongly demanded for energy and natural resource savings in the aeronautic and automobile industries. The joining of dissimilar metals or alloys such $\mathrm{Ti}$ and $\mathrm{Al}, \mathrm{Cu}$ and $\mathrm{Al}, \mathrm{Fe}$ and $\mathrm{Al}$ is one of the effective measures to reduce weight of the structures or to save rare metal. The $\mathrm{Ti}$ and $\mathrm{Al}$ structure is already used in the wing of airplanes, in which the titanium alloy crust and aluminum alloy honeycomb are welded together [1-3]. As an implication there is need for a method to utilize superior properties of dissimilar materials such as corrosive properties and strength of Ti and low weight and low cost of Al. Several approaches to weld Ti to Al have been made in the past. In the previous researches, to reduce generation of intermetallic compounds, the filler metal, and FSW welding and typical welding arrangement butt joint were used to control material percentage due to weld location. Also, butt joint was usually performed to weld the Ti and Al dissimilar metals [1-5] but there were few reports of lap welding of these alloys. Therefore, a study of the lap welding process of $\mathrm{Ti}$ and $\mathrm{Al}$ compound structure is appreciably important.

However, the performances of $\mathrm{Ti}$ and $\mathrm{Al}$ have great differences in lattice structure, melting point, heat conductivity, coefficient of linear expansion, etc. During the welding process, $\mathrm{Al}$ is severely lost at the temperature below the melting point of Ti. Composition of the weld metal is asymmetric. In addition, the laminated $\mathrm{Ti}$ and $\mathrm{Al}$ intermetallic compounds such as $\mathrm{Ti}_{3} \mathrm{Al}, \mathrm{TiAl}, \mathrm{TiAl}_{3}$, etc., are easily formed near the contacting surface between Ti and Al. As a result, it is difficult to weld the Ti and Al materials. Therefore thermal joining of aluminum and titanium has a metal- lurgical challenge due to unavoidable formation of brittle intermetallic compounds. It is necessary to effectively control the formation and growth of Ti-Al intermetallic compounds [1-3]. In this study, therefore, the effect of ultrahigh speed welding was studied because the formation of intermetallic compounds should be reduced by such high speed welding. To perform ultra-high speed welding, a single-mode fiber laser of a very small focused beam diameter with an ultra-high power density was used.

The single-mode fiber lasers have been initially developed for communication, but at the present they are widely applied to various industrial production processes such as welding, cutting, marking, etc. A single-mode fiber laser has several magnificent merits in comparison with the others. A single-mode fiber laser is compact and has a long life. It has high quality and high efficiency, and it can be easily focused to an extremely small spot than others. And thereby an ultra-high power density can be achieved. Figure 1 shows comparison of a power density among typical

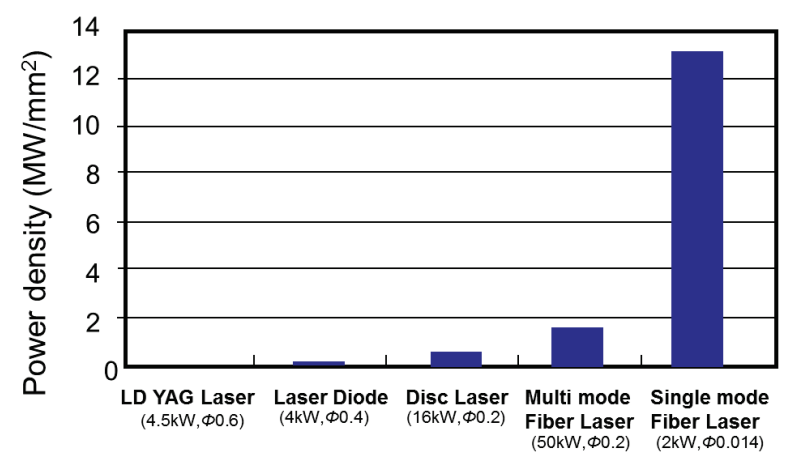

Fig. 1 Comparison of power densities of respective lasers. 
lasers such as LD-pumped YAG laser, diode laser, disc laser, multi-mode laser and single-mode fiber laser. As known, a single-mode fiber laser has the highest power density among them. The laser with a higher power/energy density can produce a deeper penetration weld or achieve a higher welding speed than lasers with a lower power density at the same powers [6].

In this study, therefore, laser lap welding of $\mathrm{Ti}$ and $\mathrm{Al}$ dissimilar sheets was performed with a single-mode fiber laser at an extremely high welding speed. Microstructural characteristics and formation phases of the weld fusion zones in $\mathrm{Ti}$ and $\mathrm{Al}$ were investigated by scanning electron microscope (SEM), energy dispersive X-ray spectroscopy (EDX) and microfocused X-ray diffractometer (XRD). Lap welding phenomena between $\mathrm{Al}$ and $\mathrm{Ti}$ sheets were also proposed from the microstructure and chemical compositions of laser weld beads.

\section{Materials and experimental procedures}

The materials used in experiments were pure titanium and commercially available aluminum A1050 sheets of $0.3 \mathrm{~mm}$ thickness, $30 \mathrm{~mm}$ width and $60 \mathrm{~mm}$ length. Their chemical compositions are shown in Table 1. Titanium has over $99.9 \% \mathrm{Ti}$ and $\mathrm{Al} 050$ has about $99.57 \% \mathrm{Al}$. The melting points of $\mathrm{Ti}$ and $\mathrm{Al}$, which are about $1941 \mathrm{~K}\left(1668^{\circ} \mathrm{C}\right)$ and $933 \mathrm{~K}\left(660^{\circ} \mathrm{C}\right)$, respectively, are extremely different. The difference in combination of $\mathrm{Ti}$ and $\mathrm{Al}$ or $\mathrm{Al}$ and $\mathrm{Ti}$ lap sheets was investigated as an important viewpoint in dissimilar welding.

The single-mode fiber laser with the maximum power of $2 \mathrm{~kW}$ and the wavelength of $1070 \mathrm{~nm}$ was utilized, and a laser beam parameter product (BPP) was 1.05 $\mathrm{mm} \cdot \mathrm{mrad}$. The laser beam was delivered by an optical fiber and focused in specimen surface by lens of $150 \mathrm{~mm}$ in focal length. The spot size of a laser beam was about $20 \mu \mathrm{m}$ at the focal point. A laser beam was directly irradiated on a 0.3 $\mathrm{mm}$ thick material sheets overlapped. Dissimilar welding

Table 1 Chemical compositions of titanium and aluminum.

\begin{tabular}{llllllllll}
\multicolumn{1}{l}{ Chemical composition (wt.\%) } \\
\hline Metal & $\mathrm{Ti}$ & $\mathrm{H}$ & $\mathrm{O}$ & $\mathrm{N}$ & $\mathrm{Fe}$ & $\mathrm{C}$ & & & \\
\hline $\mathrm{Ti}(\%)$ & 99.919 & 0.001 & 0.04 & 0.01 & 0.02 & 0.01 & & & \\
\hline Metal & $\mathrm{Al}$ & $\mathrm{Si}$ & $\mathrm{Cu}$ & $\mathrm{Mn}$ & $\mathrm{Fe}$ & $\mathrm{Hg}$ & $\mathrm{Zn}$ & $\mathrm{Ti}$ & $\mathrm{V}$ \\
\hline $\mathrm{Al}(\%)$ & 99.57 & 0.11 & 0.02 & 0.01 & 0.26 & 0.00 & 0.0 & 0.03 & 0.00 \\
\hline
\end{tabular}

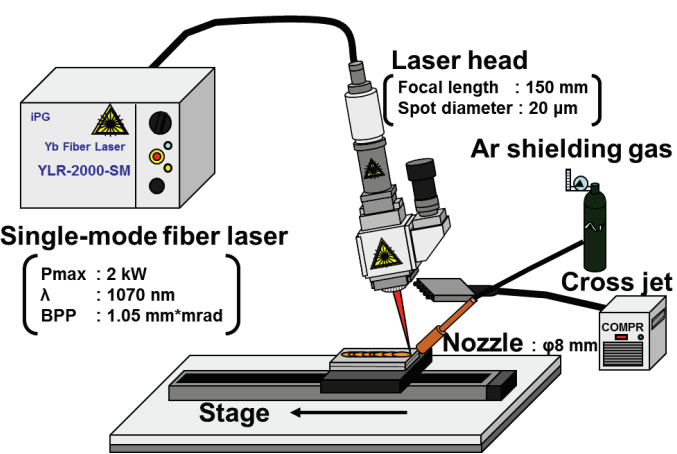

Fig. 2 Schematic experimental setup for welding of $\mathrm{Ti}$ and $\mathrm{Al}$ dissimilar metals with single-mode fiber laser. conditions used in the experiments were the laser power of $1 \mathrm{~kW}$, the welding speed of $5,10,20,30,40$ and $50 \mathrm{~m} / \mathrm{min}$ and the defocused distance of $0 \mathrm{~mm}$. Ar shielding gas of 35 $\mathrm{L} / \mathrm{min}$ was used to suppress oxidation of the upper molten surface during lap welding.

Figure 2 shows the experimental device installed for dissimilar welding of $\mathrm{Ti}$ and $\mathrm{Al} .0 .3 \mathrm{~mm}$ thick $\mathrm{Ti}$ and $\mathrm{Al}$ workpieces were fixed to a jig on high speed stage. The strengths of the dissimilar welding were evaluated by the tensile shear test at the traveling speed of $0.1 \mathrm{~mm} / \mathrm{s}$. Microstructure of the cross sections of the weld parts was observed by SEM, EDS and micro XRD to investigate the weld fusion zones for the production of a strong weld.

\section{Results and discussion}

\subsection{Ti and Al dissimilar welds produced with single- mode fiber laser at various high speeds}

It has been know until now that laser welding of $\mathrm{Ti}$ and $\mathrm{Al}$ dissimilar metals is too difficult due to their great differences in material properties and formation of intermetallic compounds.

In this study, lap welding of $\mathrm{Ti}$ and $\mathrm{Al}$ sheets was performed at extremely high welding speeds using a singlemode fiber laser to produce sound welds by the formation suppression of intermetallic compounds. Figure 3 shows top and bottom surface appearances of weld beads and SEM images of cross sections of Ti and $\mathrm{Al}$ dissimilar lap welds made with a single-mode fiber laser at $1 \mathrm{~kW}$ power and various welding speeds from 10 to $50 \mathrm{~m} / \mathrm{min}$ under the focal conditions. Under all the conditions employed, full penetration welds were obtained. Cracks were present in the weld bead of Ti side made at $5 \mathrm{~m} / \mathrm{min}$ for the $\mathrm{Al}$ (upper)-Ti (lower) combination, but sound welds were formed in all the weld beads in Fig. 3. The bottom surfaces of Ti for the $\mathrm{Al}$ (upper)-Ti (lower) combination showed complex

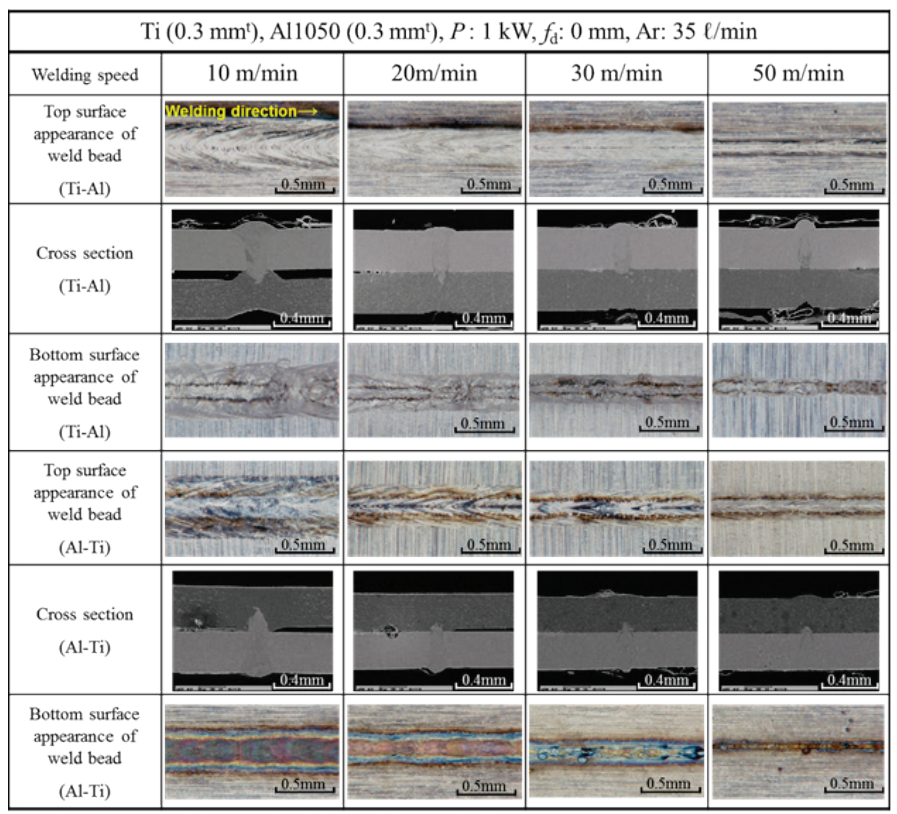

Fig. 3 Photographs of top and bottom surface appearances and cross-sectional SEM photos of Ti and Al dissimilar welds made with single-mode fiber laser at different welding speeds. 
colors because they were subjected to oxidization or nitriding from air. In the polished cross sections, the geometries of weld beads were easily seen in the Ti sheets but not in $\mathrm{Al}$ ones. The beads widths were almost similar under the same conditions. The widths were getting narrower with increasing the welding speed. In the case of $10 \mathrm{~m} / \mathrm{min}$ welding speed, welded workpieces were deformed by strong heat input effect. At the highest welding speed, it was difficult to find weld fusion zones of $\mathrm{Ti}$ and $\mathrm{Al}$, because very narrow weld zones were formed, as shown in the cross-sectional SEM photos.

\subsection{Tensile shear test results of $\mathrm{Ti}$ and $\mathrm{Al}$ dissimilar joints produced at various welding speeds}

Dissimilar welding of $\mathrm{Ti}$ and $\mathrm{Al}$ was performed by directly irradiating a single-mode fiber laser beam on the Ti-Al, Al-Ti, Al-Al and Ti-Ti sheets at the welding speed of $5 \mathrm{~m} / \mathrm{min}$ to $50 \mathrm{~m} / \mathrm{min}$. Full penetration lap welds were formed, as already shown in Fig. 3. The mechanical properties of the welds were evaluated by the tensile shear test.

Figure 4 indicates the results of the tensile shear test. The longitudinal axes of Fig. 4(a) and (b) show the obtained loads and the calculated tensile shear strength of the tensile shear test, respectively. The tensile shear strength of a material or component is expressed as $\tau=\mathrm{W} / \mathrm{A}$, where $\tau$ is the shear strength, $\mathrm{W}$ is the shear load and $\mathrm{A}$ is the welded sectional area. The welded sectional area was calculated from the weld bead length $(20 \mathrm{~mm})$ multiplied by measured joint width of a lap weld. The width was obtained as an average of three cross sections. The strength in $\mathrm{MPa}$

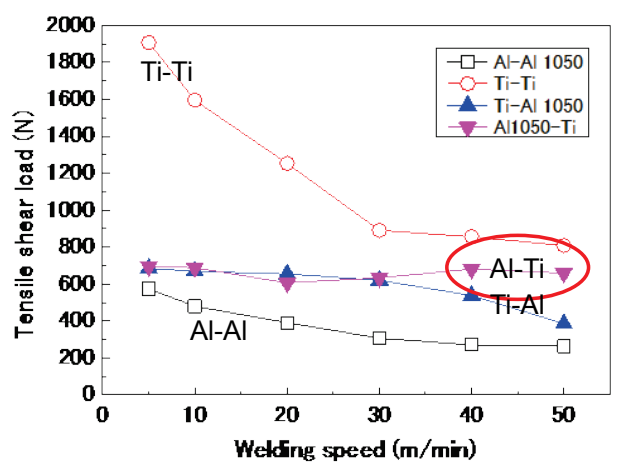

(a) Obtained loads of tensile shear test

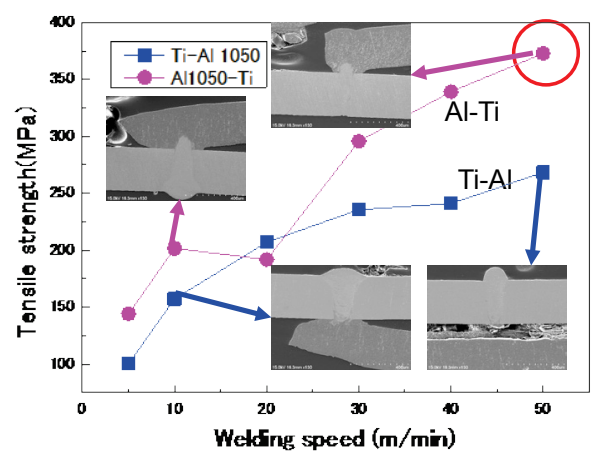

(b) Tensile shear test results of strength $(\mathrm{N})$ per $1 \mathrm{~mm}^{2}$

Fig. 4 Results of tensile shear test for $\mathrm{Ti}$ and $\mathrm{Al}$ similar and dissimilar welds: (a) tensile shear load, (b) tensile shear strength $(\mathrm{N})$ per $1 \mathrm{~mm}^{2}$.
$\left(\mathrm{N} / \mathrm{mm}^{2}\right)$ is expressed as the tensile shear strength of a welded part in order to evaluate the effect of the bead widths of welds made at various high speeds and the possibility of $\mathrm{Ti}$ and $\mathrm{Al}$ dissimilar welding using a single-mode laser.

The tensile shear loads of Ti-Ti welds were the highest, while those of Al-Al welds were the smallest. The loads of the Al-Ti and Ti-Al dissimilar welds were slightly higher than those of Al-Al welds. The loads of welds were about $700 \mathrm{~N}$ (for $20 \mathrm{~mm}$ wide) except Ti(upper)-Al(lower) welds produced at 40 and $50 \mathrm{~m} / \mathrm{min}$ welding speed. In the case of Ti-Ti and Al-Al similar welds, the fracture occurred in the weld beads, and accordingly the loads decreased with an increase in the welding speed due to the decreased welding area. In the most cases of Al-Ti and Ti-Al welds the fracture of the specimens occurred in the base $\mathrm{Al}$, as shown in Fig. 4 (b), and thus the loads were almost equal. The decreased loads were attributed to the fracture in the narrow weld beads. The tensile shear strength increased with an increase in the welding speed accompanying with a decrease in the welding area, and therefore extremely high welding speed $(50 \mathrm{~m} / \mathrm{min}$ in this study) is good to dissimilar weldability for $\mathrm{Al}$ and Ti. Furthermore the single-mode laser beam which has high power density can achieve extremely high welding speeds. When Al was located on the upper side of Ti during laser welding, better weldability could be obtained than that of the opposite Ti-Al combination. The cross-sectional photos of fractured specimens of the tensile shear test show that the specimen made at 10 $\mathrm{m} / \mathrm{min}$ welding speed was fractured in the Al base metal because the weld was strongly jointed with enough welds size without fracture from intermetallic compounds zone. Workpieces of $\mathrm{Al}$ (upper)-Ti (lower) dissimilar welds at $50 \mathrm{~m} / \mathrm{min}$ were fractured at base metal nearby weld zones even though the weld beads were very narrow, and the reason may be the reduction in brittle intermetallic compounds leading to a strong joint of $\mathrm{Al}$ and $\mathrm{Ti}$. On the other hand, $\mathrm{Ti}$ (upper)-Al (lower) dissimilar welds at $50 \mathrm{~m} / \mathrm{min}$ fractured in the weld zone. The difference may be attributed to the formation location of the Ti-rich zone and intermetallic compounds to the lapped interface.

The tensile shear test in this study shows a different tendency from the previous research results $[1-5,7]$, showing easy fracture in $\mathrm{Ti}$ and $\mathrm{Al}$ welds zones produced only at high speeds due to brittle intermetallic compounds near the interface of two sheets, but the fracture in Al base metal in the other welds. To understand the effects of welding speed and material upper-lower combination on weldability, the microstructural characteristics should be elucidated by SEM (Scanning electron microscope), EDX (energy dispersive X-ray microanalyzer), XRD (X-ray diffraction method) and TEM (Transmission electron microscope).

\subsection{Microstructural characteristics of interface zone}

To know the reason for the tendency difference of tensile shear test results, microstructural characteristics were analyzed. In order to understand the difference in welds characteristics according to the change in welding speed, laser weld zones between $\mathrm{Ti}$ and $\mathrm{Al}$ were investigated in detail. The cross-sectional SEM photos, the EDX line analytical results across the centerline of the weld beads, and 
spot analytical results of respective characteristic fusion zones are shown in Fig. 5. In Fig. 5(a) of Ti (upper)-Al (lower) dissimilar welds made at $1 \mathrm{~kW}$ and $10 \mathrm{~m} / \mathrm{min}$, a small amount of $\mathrm{Al}$ element was distributed all over in the weld metal of the upper Ti sheet while Ti is not distributed in the $\mathrm{Al}$ sheet side. In Fig. 5(b) of $\mathrm{Ti}$ (upper) - $\mathrm{Al}$ (lower) dissimilar weld produced at $50 \mathrm{~m} / \mathrm{min}$, the change in the compositions is appreciably present neat the interface of lapped sheets. In the other welds, the compositional change between $\mathrm{Ti}$ and $\mathrm{Al}$ occurred appreciably in the $\mathrm{Al}$ side slightly away from the interface of the sheets. Ti was distributed slightly into $\mathrm{Al}$ sheet, and Ti enriched area reduced with increasing the welding speed. And a small amount of Al was distributed into Ti side weld metal under all conditions. Both of $\mathrm{Ti}$ (upper) - $\mathrm{Al}$ (lower) and $\mathrm{Al}$ (upper) - Ti (lower) dissimilar welding at $10 \mathrm{~m} / \mathrm{min}$ were subjected to overheating, and this overheating should cause the welding distortion or deformation as shown in Fig.5 (a) and (c).

Thus ' $A$ ' area of Fig. 5 (d) was observed, and EDX mapping analysis result is shown in Fig. 6. Ti distributed into $\mathrm{Al}$ area partially but it seemed to be not fully mixed with $\mathrm{Al}$ and just replaced. And it was confirmed that a small amount of $\mathrm{Al}$ was easily distributed into $\mathrm{Ti}$, as shown in Fig. 6.

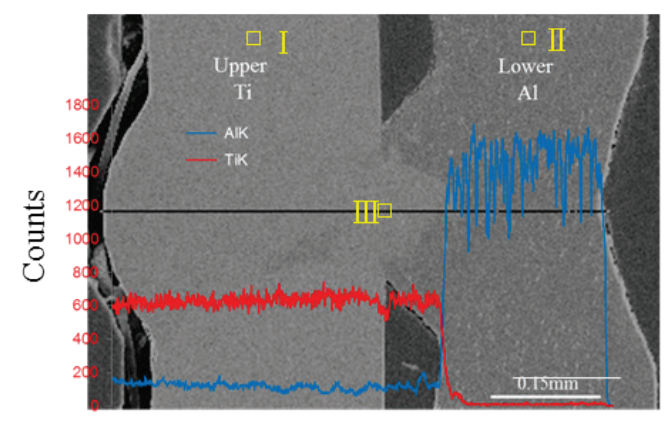

(a)

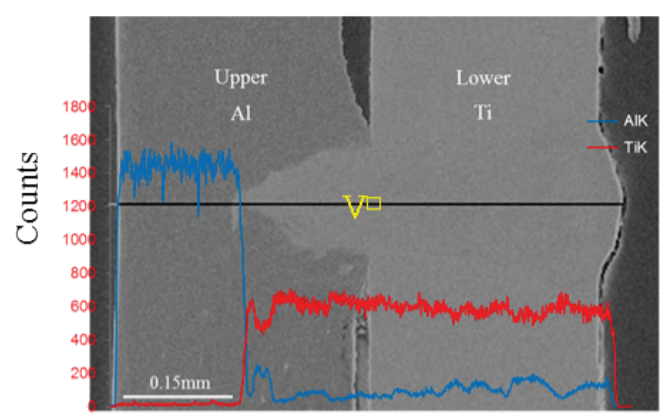

(c)

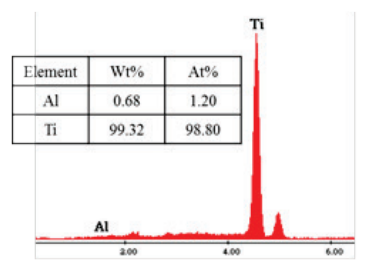

I Pure Ti
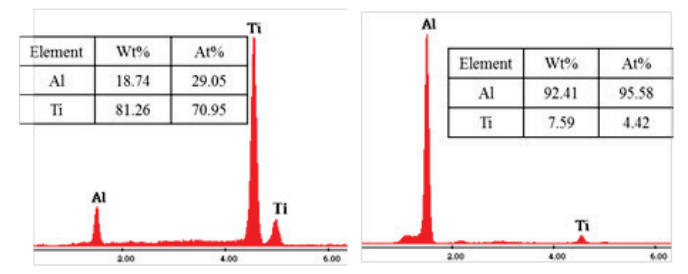

III (a)

$\mathrm{IV}(\mathrm{b})$

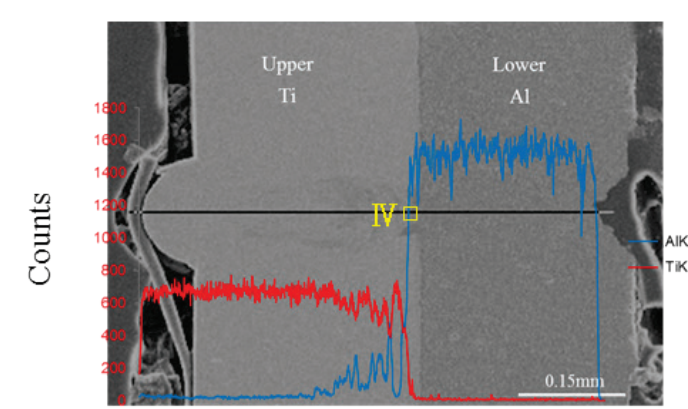

(b)

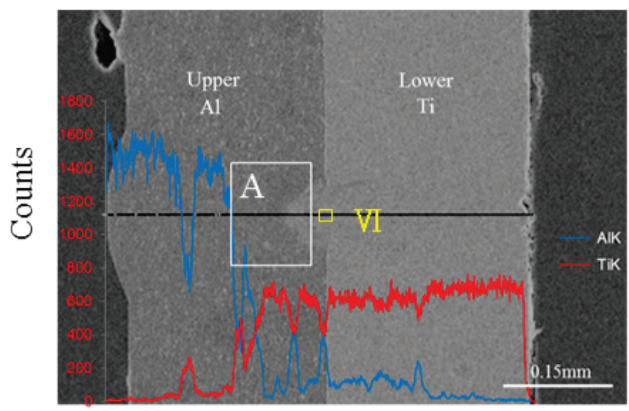

(d)

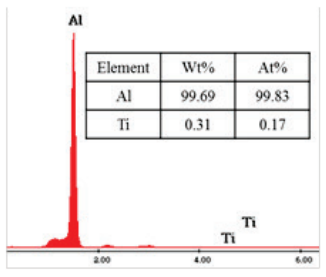

II Pure $\mathrm{Al}$

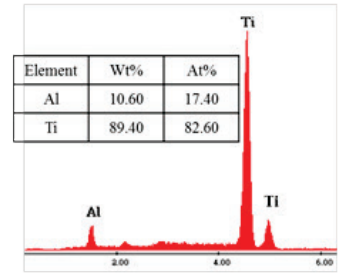

$\mathrm{V}(\mathrm{c})$

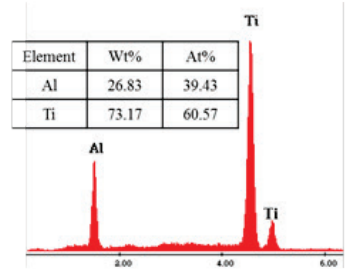

$\mathrm{VI}(\mathrm{d})$

Fig. 5 Cross-sectional SEM photos and EDX line analysis results of dissimilar welds at $1 \mathrm{~kW}$ laser power in various specimens locations at different welding speeds. : (a) Ti(upper)-Al(lower), $10 \mathrm{~m} / \mathrm{min}$ welding speed; (b) Ti(upper)-Al(lower), $50 \mathrm{~m} / \mathrm{min}$ welding speed; (c) Al(upper)-Ti(lower), $10 \mathrm{~m} / \mathrm{min}$ welding speed; (d)Al(upper)-Ti(lower), $50 \mathrm{~m} / \mathrm{min}$ welding speed, and EDX analysis of pure Ti I, pure Al- II part(a)-III, part(b)-IV, part(c)-V and part (d)-VI, respectively. 


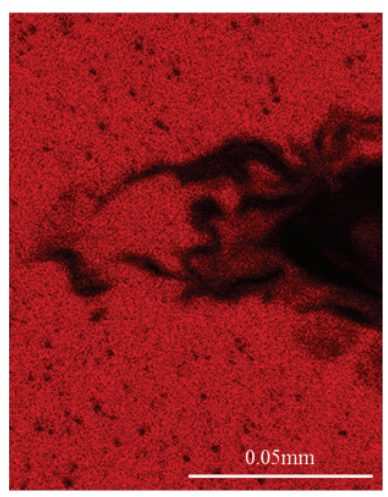

(a) $\mathrm{A}-\mathrm{Al}$

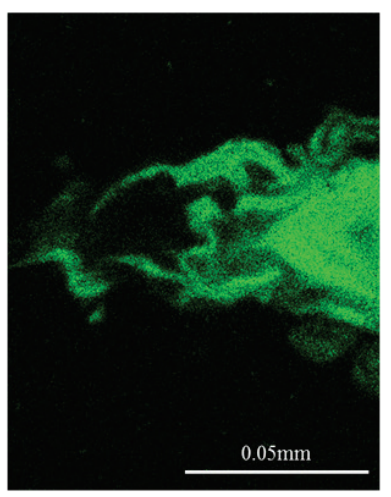

(b) A-Ti
Fig. 6 Results of EDX mapping analysis of 'A' marked in Fig. 5 (d) : (a) - Al(red), (b)- Ti(green).

The parts marked in photos of Fig. 5(a) such as I, II, III, IV, $\mathrm{V}$ and VI were observed using line and spot EDX analysis to identify the specific particle constituent. I and II marks of the pure Ti and Al base metals and III to VI near the central parts of weld fusion zones were observed, and respective spot EDX analysis results are shown in Fig. 5. Both of Ti and $\mathrm{Al}$ existed in the weld fusion zones of all conditions. A small amount of $\mathrm{Al}$ was distributed into $\mathrm{Ti}$ sheets, and $\mathrm{Al}$ and $\mathrm{Ti}$ were mixed in the interface zone, but Ti was hardly distributed into $\mathrm{Al}$ sheet in (a). The result of EDX line analysis of (b) shows admixed zone around IV which was area from an interface zone to a top bead about $0.15 \mathrm{~mm}$. The results of EDX analysis of (c) and (d) show almost the same pattern, Ti was locally distributed into Al sheets, but relatively very small amount of Al was distributed into Ti sheet because small amount of Al easily included in $\mathrm{Ti}$ as Ti solid solution. The zone including intermetallic compounds was changed by welding speed. If the welding speed increased, the weld zone was reduced.

From the results of EDX analysis, it was found that the area of compounded zone and welding deformation could be reduced by using extremely high speed. Therefore, extremely high welding speed with high power density laser (such as single-mode fiber laser) could suppress the compound zones, where intermetallic phases such as $\mathrm{Ti}_{3} \mathrm{Al}$, $\mathrm{TiAl}, \mathrm{TiAl}_{3}$, and so on were formed.

To recognize the formation of intermetallic phases in the laser weld zones exactly, the zones marked as III to VI in Fig. 5 were subjected to XRD analyses and the results are shown in Fig. 7. Figures 7 (b) and (d) show pure base metal peak of Al and Ti clearly. At the high welding speed, peaks of $\mathrm{Al}$ and $\mathrm{Ti}$ were present but it was rather difficult to find out peaks of intermetallic compounds. On the other hand, Figures 7 (a) and (c) show messy peaks pattern with intermetallic compounds such as TiAl and $\mathrm{Al}_{3} \mathrm{Ti}$. The XRD analytical result of $\mathrm{Ti}$ and $\mathrm{Al}$ dissimilar welds at $10 \mathrm{~m} / \mathrm{min}$ (a) shows the most messy peak in Fig.7, and this condition had the lowest tensile strength in this research.

The single-mode fiber laser could achieve welding at high welding speed because the laser could be locally irradiated and produce a molten pool easily in very high speed welding. The heating and cooling rates at extremely high

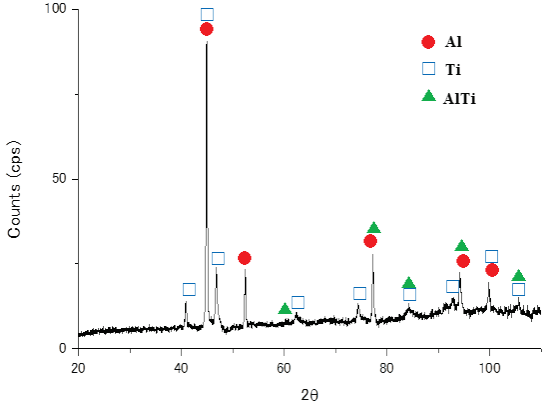

(a) III

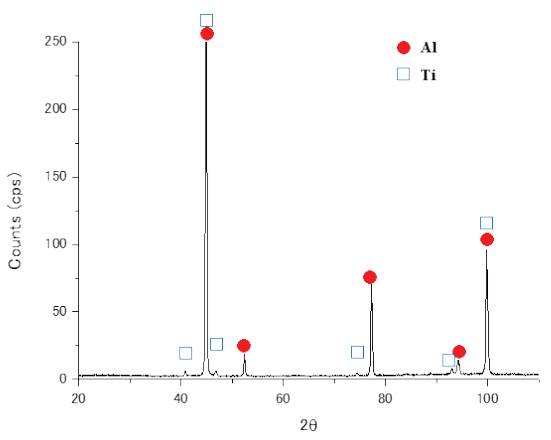

(b) IV

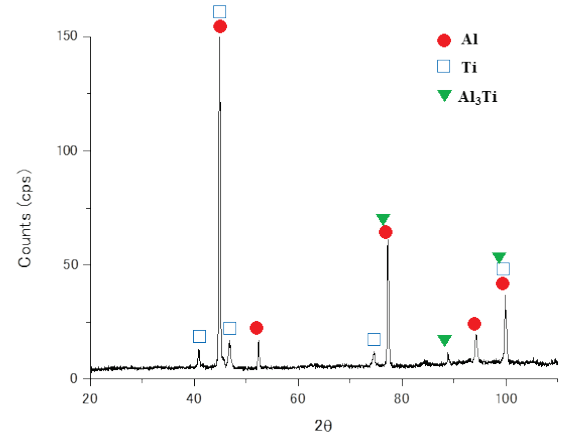

(c) $\mathrm{V}$

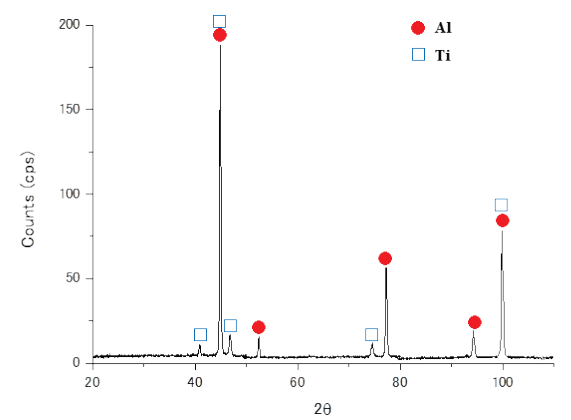

(d) VI

Fig. 7 Micro XRD analytical results of welded zones of Ti and $\mathrm{Al}$ dissimilar welds which marked at Fig.5 : (a) III, (b) IV, (c) V and (d) VI, respectively.

speed are too high to diffusion bonding, and so the atoms cannot fully diffuse during welding. It was confirmed that an extremely high welding speed could suppress the formation of intermetallic compounds using single-mode fiber laser of high power density. Consequently, this leads to the production of a strong weld. 
This result suggests much production possibility of strong $\mathrm{Ti}$ and $\mathrm{Al}$ dissimilar welds using single-mode fiber laser at extremely high welding speed.

\section{Conclusions}

Ti and Al dissimilar lap welding was carried out at various welding speeds and upper-lower specimen combinations using single-mode fiber laser which had very high power density in order to find out a possibility of $\mathrm{Ti}$ and $\mathrm{Al}$ dissimilar lap welding and to elucidate the welding phenomena. The results of the tensile shear test show that $\mathrm{Ti}$ and $\mathrm{Al}$ dissimilar weld joints had higher tensile shear load than $\mathrm{Al}$ and $\mathrm{Al}$ similar ones, and the apparent tensile shear strength increased with increasing the welding speed under all conditions. According to SEM observation, EDS and XRD analyses, when the welding speed was $50 \mathrm{~m} / \mathrm{min}$ high at $1 \mathrm{~kW}$ laser power, intermetallic compounds were sufficiently reduced. On the other hand, if the welding speed was $10 \mathrm{~m} / \mathrm{min}$ low, intermetallic compounds were formed more easily than high speed one, but it was enough to reduce brittle intermetallic compound formation using high energy density laser beam with a very small spot size.

It was confirmed that the extremely high welding speed and high energy density laser beam could reduce the formation area and amount of intermetallic compounds. Therefore, the research results of single-mode fiber laser at high welding speeds suggest much production possibility of strong dissimilar weld joints by reducing intermetallic compounds.

\section{Acknowledgment}

This work was conducted as a part of A-STEP "Highquality and high-efficiency processing technology of titanium alloy using a high brightness laser process control method"

\section{References}

[1] C. Leyens, Titanium and Titanium Alloys ; Fundamentals and Applications, WILEY-VCH GmbH \& Co. $\mathrm{KGaA}$, (2002).

[2] S.Chen, L.Li, Y.Chen and J.Huang1, Joining mechanism of $\mathrm{Ti} / \mathrm{Al}$ dissimilar alloys during laser weldingbrazing process, Journal of Alloys and Compounds, vol.509, pp.891-898, (2011).

[3] Y.C. Chen and K.Nakata, Microstructural characterization and mechanical properties in friction stir welding of aluminum and titanium dissimilar alloys, Materials and Design, vol.30, pp.469-474, (2009).

[4] Katayama Seiji, Laser Welding, Journal of the Japan welding society, vol.78, no.2, pp.124-138, (2009)

[5] Katayama Seiji, Laser Welding for Manufacturing Innovation, Journal of the Japan welding society, vol.78, no.8, pp.682-692, (2009)

[6] Hideyasu SHAMOTO, Kazuhisa MIKAME, The feature of High Power Single Mode Fiber Laser Processing, Proceedings of the $72^{\text {nd }}$ Laser Materials Processing Conference, pp.31-34, (2009)

[7] S.D.Meshram, T.Mohandas, G.Madhusudhan Reddy, Friction welding of dissimilar pure metals, Journal of Materials Processing Technology, vol.184, pp.330-337, (2007)

[8] Akira Matsunawa, Naoki Seto, Jong-Do Kim, Masami Mizutani Seiji Katayama, Observation of Keyhole and Molten Pool Behaviour in High Power Laser Welding, Trans. JWRI, vol.30, no.1, pp.13-27, (2001)

[9] Akira Matsunawa, Jong-Do Kim, Naoki Seto, Masami Mizutani, Seiji Katayama, Dynamic of keyhole and molten pool in Laser welding, Journal of Laser Applications, vol.10, no.6, pp.247-254, (1998)

(Received: August 7, 2012, Accepted: March 4, 2013) 